\title{
The Role of Negative-Pressure Wound Therapy in Latissimus Dorsi Flap Donor Site Seroma Prevention: A Cohort Study
}

\author{
Apichai Angspatt, Thana Laopiyasakul, Pornthep Pungrasmi, Poonpissamai Suwajo \\ Division of Plastic and Reconstructive Surgery, Department of Surgery, Faculty of Medicine, Chulalongkorn University, Bangkok, Thailand
}

Background Donor site seroma is the most common complication after latissimus dorsi (LD) flap harvest. This study aimed to evaluate the efficacy of negative-pressure wound therapy (NPWT) in preventing donor site seroma formation after the harvest of an LD flap for breast reconstruction.

Methods In this prospective matched-pair study, 40 patients in whom an LD flap was harvested for breast reconstruction were enrolled. NPWT was used in 20 patients, and in a control group composed of another 20 patients, the conventional donor site dressing technique was used. Information was collected regarding postoperative complications, the incidence of seroma, total drainage volume, the number of percutaneous seroma aspirations, and the volume aspirated.

Results In the NPWT group, the incidence of seroma formation after drain removal was significantly lower than in the control group ( $15 \%$ vs. $70 \%$; odds ratio $=0.07$; relative risk, 0.24). Both the mean percutaneous aspirated volume $(P=0.004)$ and the number of percutaneous aspirations $(P=0.001)$ were also significantly lower in the NPWT group. There were no significant differences in the total drainage volume or the duration of wound drainage between the NPWT dressing group and the control group $(P>0.05)$.

Conclusions This study showed that NPWT is a promising tool for reducing the incidence of seroma formation after removing the drain at the donor site after LD flap harvesting. It is a simple and safe technique.

Keywords Mammaplasty / Surgical flaps / Superficial back muscles / Seroma / Negativepressure wound therapy
Correspondence: Apichai Angspatt Division of Plastic and Reconstructive Surgery, Department of Surgery, Faculty of Medicine, Chulalongkorn University, Rama IV Road, Phatumwan, Bangkok 10330, Thailand Tel: +66-81-491-3657 Fax: +66-2-256-4120

E-mail: aangspatt@hotmail.com

Received: 25 Jan 2017 • Revised: 22 Apr 2017 • Accepted: 26 May 2017

pISSN: 2234-6163 • elSSN: 2234-6171 • https://doi.org/10.5999/aps.2017.44.4.308・ Arch Plast Surg 2017;44:308-312

No potential conflict of interest relevant to this article was reported.

\section{INTRODUCTION}

Latissimus dorsi (LD) musculocutaneous flaps are commonly used in reconstructive surgery, particularly in breast reconstruction. Donor site seroma is the most common complication following this procedure, with an incidence varying from $30 \%$ to
83\% [1-4]. Seroma can be caused by many contributing factors, including shear between subcutaneous tissue and the underlying muscle, dead space, and leakage from lymphatic and vascular channels [5]. Although most patients are asymptomatic, sequelae such as discomfort and infection can be anticipated. Treatments for this problem and preventive techniques have been re- 
ported. These methods include avoiding electrocauterization, the quilting of skin flaps and/or the use of fibrin sealant, endoscopic harvest, long-term drainage, pressure dressings, repeated aspiration, sclerotherapy, and steroid injections [5-10]. Quilting of the donor site is the most commonly used technique. However, it is time-consuming and in some patients, exacerbated postoperative pain and restricted shoulder movement have been reported.

The use of negative-pressure wound therapy (NPWT) to stabilize a skin graft by immobilizing the graft, limiting shear stresses, and eliminating fluid collection was described by Schneider et al. [11] and Blackburn et al. [12] in 1998. NPWT addresses factors similar to the mechanisms that cause seroma after LD flap harvest. The aim of this study was to evaluate the efficacy of NPWT as an alternative technique for preventing seroma formation at LD flap donor sites.

\section{METHODS}

\section{Patients and methods}

The study was approved by the ethics committee of the Faculty of Medicine at King Chulalongkorn Memorial Hospital (IRB No. 030/55). Forty patients, ranging in age from 29 to 55 years, who underwent breast reconstruction using an $\mathrm{LD}$ flap between January 2009 and December 2012 at King Chulalongkorn Memorial Hospital in Thailand were enrolled in this matched-pair cohort study. All reconstructive procedures were performed by the same group of surgeons. Patients were divided into an experimental group and a control group. Patients who were operated on by the same surgeon were grouped into pairs and then randomly assigned to the experimental or control group. In the experimental group, the LD donor site was dressed using NPWT (Renasys, Smith and Nephew, Oklahoma, USA) with the suction tube in the midline groove. The conventional method of dressing was used in the control group. The LD musculocutaneous flaps were raised using the conventional method. Skin flaps approximately the size of the previous nipple-areolar complex were used in most cases, except for 3 cases in the experimental group and 5 cases in the control group, in which large skin flaps were used. In all cases, $90 \%$ of the LD muscle from the entire back was raised. All thoracodorsal nerves were transected, as well as most of the muscle around the pedicle, to prevent involuntary postoperative muscle contraction. Textured round implants with volumes of $175-350 \mathrm{~mL}$ (Mentor) were placed underneath the muscle in all cases, except for 1 case in each group. No other special techniques, such as quilting sutures, sealant, or glue, were used.

This work was reported in accordance with the Strengthening the Reporting of Observational Studies in Epidemiology (STROBE) criteria [13].

\section{Technique}

One suction drain was placed underneath the LD donor site skin flap in both groups. The dressing was then placed on top of the closed wound.

In the experimental group, after the donor site wound was closed, gauze dressing was placed upon the wound. The first layer of the adhesive drape sheet was placed over the gauze dressing and the entire dissected field of the $\mathrm{LD}$ flaps to prevent skin maceration. A piece of reticulated open-cell foam was trimmed to a size slightly smaller than the adhesive drape sheet, and then the other adhesive drape sheet and the vacuum tube were placed on top of the foam, just as in conventional NPWT dressing. The NPWT was left in place for 3 days with constant pressure between -80 and $-125 \mathrm{~mm} \mathrm{Hg}$. Subsequently, a conventional pressure dressing using an elastic bandage was put in place.

In the control group, the donor site wound was dressed with gauze and adhesive tape, or a transparent film with a pad. The pressure dressing was put in place using an elastic bandage.

The drain was removed when the drainage volume was less than $30 \mathrm{~mL}$ per day. The volume of all seromas and the duration of wound drainage were recorded. Postoperative follow-up was carried out every week in the first month, followed by 3 months, 6 months, and 1 year after surgery. All patients who presented with a symptomatic seroma on the back were treated with percutaneous needle aspiration, and the aspirated volume was recorded.

\section{Outcome measures}

Seroma was defined as clinically noticeable fluid collection at the donor site after the drain had been removed. The incidence of seroma formation was the primary outcome. Seromas that developed after the drain had been removed 1-2 weeks after surgery were treated by percutaneous aspiration. The aspirated volume and the number of percutaneous aspirations were recorded. The aspirated seroma volume and the drainage volume from the suction drain were recorded as the total drainage volume.

The secondary outcome measures were the number of percutaneous aspirations and the total percutaneous aspirated volume. All wound complications were also recorded.

\section{Statistical analysis}

Data were analyzed using SPSS ver. 17.0 (SPSS Inc., Chicago, IL, USA). The Student t-test was used to derive all P-values. Sta- 
tistical significance was defined at $\alpha=0.05$.

\section{RESULTS}

Forty patients were enrolled in the study. Twenty patients were included in each group. All patients received follow-up until 1 year after surgery. There were no statistically significant differences in patient demographic data between the 2 groups (Table 1 ).

NPWT is shown in Fig. 1. In the NPWT group, the incidence of seroma formation was significantly lower than in the control group ( $15 \%$ vs. $70 \%$; odds ratio $=0.07$; relative risk, 0.24$)$. Both the mean percutaneous aspirated volume $(\mathrm{P}=0.004)$ and the numbers of percutaneous aspirations $(\mathrm{P}=0.001)$ were also significantly lower in the NPWT group (Table 2). There were no significant differences in the total drainage volume, the duration of wound drainage, or the length of hospital stay between the NPWT dressing group and the control group $(\mathrm{P}>0.05)$.

\begin{tabular}{|c|c|c|c|}
\hline Dermographic data & $\begin{array}{l}\text { Control } \\
(n=20)\end{array}$ & $\begin{array}{c}\text { NPWT } \\
(n=20)\end{array}$ & P-value ${ }^{a)}$ \\
\hline Age (yr) & 43.1 & 42.2 & $>0.05$ \\
\hline BMI $\left(\mathrm{kg} / \mathrm{m}^{2}\right)$ & 20.2 & 20.6 & $>0.05$ \\
\hline Immediate breast reconstruction & 17 & 19 & $>0.05$ \\
\hline Delayed breast reconstruction & 3 & 1 & $>0.05$ \\
\hline
\end{tabular}

Three patients developed minor skin blebs from the adhesive drape sheet in the NPWT group. They all healed spontaneously after conservative treatment. An infected seroma was found in 1 patient in the control group. She was treated with antibiotics and subsequently healed.

\section{DISCUSSION}

Seroma formation at the donor site after the harvest of an LD flap is quite a common complication. Many treatment modalities have been developed in attempts to solve this problem. Schwabegger et al. [5] defined some of possible causes of seroma formation. These mechanisms include the friction of the

\begin{tabular}{|c|c|c|c|}
\hline Data & $\begin{array}{l}\text { Control } \\
\text { group } \\
(n=20)\end{array}$ & $\begin{array}{c}\text { NPWT } \\
(n=20)\end{array}$ & P-value ${ }^{a)}$ \\
\hline Total drainage, $\mathrm{mL}$ & 564 & 418 & $>0.05$ \\
\hline Time to drain removal, days & 6.8 & 6.35 & $>0.05$ \\
\hline $\begin{array}{l}\text { No. of patients in whom a seroma } \\
\text { formed (\%) }\end{array}$ & $14(70)$ & $3(15)$ & $\begin{array}{l}\mathrm{RR}=0.24 \\
\mathrm{OR}=0.07\end{array}$ \\
\hline Percutaneous aspirated volume (mL) & 193 & 26 & 0.004 \\
\hline $\begin{array}{l}\text { No. of percutaneous aspirations per } \\
\text { person }\end{array}$ & 3 & 1 & 0.001 \\
\hline \multicolumn{4}{|c|}{$\begin{array}{l}\text { NPWT, negative-pressure wound therapy; RR, relative risk; OR, odds ratio. } \\
\text { a)Student t-test. }\end{array}$} \\
\hline
\end{tabular}

\section{Fig. 1. Negative pressure wound therapy}

(A) Donor site area. (B) The donor site wound was closed with gauze dressing, in the same manner as the conventional dressing, and the first layer of the adhesive drape sheet was placed over the gauze dressing and the dissected field of the latissimus dorsi flap to prevent skin maceration. (C) A piece of reticulated open-cell foam was trimmed to a size slightly smaller than the adhesive drape sheet, and then the vacuum tube was placed. (D) Another adhesive drape sheet was applied.
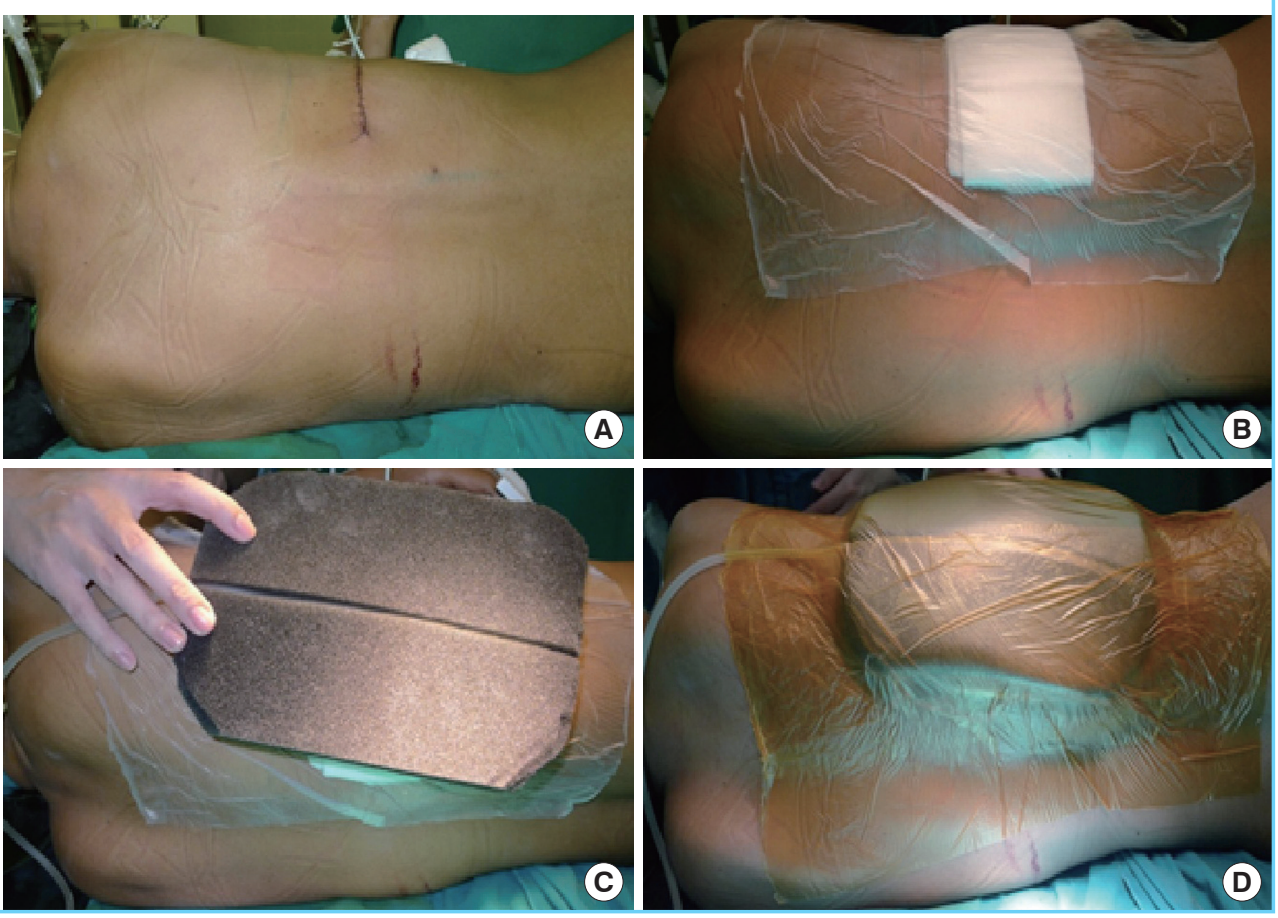
wound layers and fat necrosis from liberal handling of the electrocautery knife.

The use of quilting sutures (the Chippendale technique) to eliminate dead space at the donor site of an LD flap was first described by Titley et al. [6] in 1997. This method has been reported to be the most effective technique, with an incidence of seroma ranging from $0 \%$ to $45.6 \%$ [14-17]. However, some minor adverse effects might occur after quilting sutures, such as back pain and limitations of shoulder movement, in addition to the time-consuming nature of the procedure.

The mechanisms of NPWT that contribute to graft stabilization have been well described in the literature, and include limiting shear stresses and totally immobilizing the graft [11]. In this study, we applied NPWT to the donor site of LD flaps in order to limit shear stresses between subcutaneous tissue and the underlying muscle, with the goal of decreasing seroma formation. When the NPWT group was compared with the conventional dressing group, we found that the incidence of seroma formation after drain removal decreased from $70 \%$ to $15 \%$. NPWT also reduced the number of percutaneous seroma aspirations from 3 to 1 and decreased the aspirated volume from 193 to 26 $\mathrm{mL}$. However, the total drainage volume was not significantly different between the 2 groups. NPWT is simple to apply, and no other procedures capable of causing discomfort were required. However, NPWT is substantially more expensive than the conventional dressing method. Minor complications, such as skin blebs, may arise from indelicate stripping of the film, but in our study, such complications mostly healed after conservative treatment. There are several limitations of this study. First, the sample size was rather small, and the evaluation of the presence of a seroma was subjective. Second, this was not a blinded study, so potential bias must be considered.

The incidence of seroma formation after drain removal was significantly lower in the NPWT group than in the conventional dressing group. Dressing the donor site with NPWT also reduced the number of percutaneous seroma aspirations and the volume that was aspirated. This study showed that NPWT is a promising tool for reducing the incidence of seroma formation at the donor site after LD flap harvesting. It is a simple and safe technique.

\section{REFERENCES}

1. Rios JL, Pollock T, Adams WP Jr. Progressive tension sutures to prevent seroma formation after latissimus dorsi harvest. Plast Reconstr Surg 2003;112:1779-83.

2. Menke H, Erkens M, Olbrisch RR. Evolving concepts in breast reconstruction with latissimus dorsi flaps: results and follow-up of 121 consecutive patients. Ann Plast Surg 2001; 47:107-14.

3. Delay E, Gounot N, Bouillot A, et al. Autologous latissimus breast reconstruction: a 3-year clinical experience with 100 patients. Plast Reconstr Surg 1998;102:1461-78.

4. Daltrey I, Thomson H, Hussien M, et al. Randomized clinical trial of the effect of quilting latissimus dorsi flap donor site on seroma formation. Br J Surg 2006;93:825-30.

5. Schwabegger A, Ninkovic M, Brenner E, et al. Seroma as a common donor site morbidity after harvesting the latissimus dorsi flap: observations on cause and prevention. Ann Plast Surg 1997;38:594-7.

6. Titley OG, Spyrou GE, Fatah MF. Preventing seroma in the latissimus dorsi flap donor site. Br J Plast Surg 1997;50:1068.

7. Porter KA, O'Connor S, Rimm E, et al. Electrocautery as a factor in seroma formation following mastectomy. Am J Surg 1998;176:8-11.

8. Weinrach JC, Cronin ED, Smith BK, et al. Preventing sero$\mathrm{ma}$ in the latissimus dorsi flap donor site with fibrin sealant. Ann Plast Surg 2004;53:12-6.

9. Lin CH, Wei FC, Levin LS, et al. Donor-site morbidity comparison between endoscopically assisted and traditional harvest of free latissimus dorsi muscle flap. Plast Reconstr Surg 1999;104:1070-7.

10. Zide BM. To reduce your seroma rate. Plast Reconstr Surg 1999;103:1098-9.

11. Schneider AM, Morykwas MJ, Argenta LC. A new and reliable method of securing skin grafts to the difficult recipient bed. Plast Reconstr Surg 1998;102:1195-8.

12. Blackburn JH 2nd, Boemi L, Hall WW, et al. Negative-pressure dressings as a bolster for skin grafts. Ann Plast Surg 1998;40:453-7.

13. von Elm E, Altman DG, Egger M, et al. The Strengthening the Reporting of Observational Studies in Epidemiology (STROBE) statement: guidelines for reporting observational studies. Int J Surg 2014;12:1495-9.

14. Sajid MS, Betal D, Akhter N, et al. Prevention of postoperative seroma-related morbidity by quilting of latissimus dorsi flap donor site: a systematic review. Clin Breast Cancer 2011; 11:357-63.

15. Dancey AL, Cheema M, Thomas SS. A prospective randomized trial of the efficacy of marginal quilting sutures and fibrin sealant in reducing the incidence of seromas in the extended latissimus dorsi donor site. Plast Reconstr Surg 2010; 125:1309-17.

16. Ali SN, Gill P, Oikonomou D, et al. The combination of fibrin glue and quilting reduces drainage in the extended latis- 
simus dorsi flap donor site. Plast Reconstr Surg 2010;125: 1615-9.

17. Gisquet H, Delay E, Paradol PO, et al. Prevention of seroma by quilting suture after harvesting latissimus dorsi flap: the “Chippendale” technic. Ann Chir Plast Esthet 2010;55:97103. 